\title{
“FIZ DE MINHA VONTADE DE SAÚDE, DE VIDA, MINHA FILOSOFIA...". NIETZSCHE E O PROBLEMA DA MEDICINA EM "ECCE HOMO"*
}

\author{
Scarlett Marton** \\ smarton@usp.br
}

\begin{abstract}
RESUMO Em "Ecce Homo", Nietzsche apresenta-se ao mesmo tempo como terapeuta e enfermo. Se nos seus escritos ele concebe o filósofo como médico da cultura, nesse livro é também como paciente que comparece. Compreender as razões que o levaram a proceder dessa maneira em "Ecce Homo", é o problema que presidirá este trabalho. Tomando como ponto de partida a análise dos primeiros capítulos do livro, contamos de início esclarecer a dupla condição de seu autor: a de terapeuta e enfermo, explorando em particular sua ideia de se tomar em mãos. Examinando o último capítulo à luz dessas análises, estaremos então em condições de nos perguntar sobre o que permite a Nietzsche passar da condição de médico de si mesmo à de médico da cultura. Esperamos elucidar desse modo a relação intrínseca que ele afirma existir entre suas concepções de filosofia e vida.
\end{abstract}

Palavras-chave Nietzsche, medicina, cultura, transvaloração, filosofia, vida.

ABSTRACT In "Ecce Homo", Nietzsche presents himself, at the same time, both as a doctor and a sufferer. If in his writings he conceives the philosopher

* Tradução brasileira da conferência intitulada “'Je fis de ma volonté de santé, de vie, ma philosophie...' Nietzsche et le problème de la médecine dans Ecce homo", apresentada no IX Congresso Internacional do GIRN (Groupe International de Recherches sur Nietzsche), na Universidade da Basileia, em 21 de junho de 2016. Artigo submetido em 19/07/2017. Aceito em 21/09/2017.

** USP - Universidade de São Paulo, São Paulo, SP, Brasil. Professora Titular de Filosofia Contemporânea da USP. 
as the physician of the culture, in this book he also appears as a patient. The present paper aims at questioning about the reasons which led Nietzsche to adopt this way of doing in "Ecce Homo". Taking the analysis of the first chapters of this book as a start point, we intend to clarify, first of all, its authors' dual condition as both a doctor and a sufferer, particularly exploring his idea of taking himself in hand. Then examining the last chapter of the book in the light of these analyses, we attempt to find out what allows Nietzsche to make the transition from his condition of being his own doctor to the condition of physician of the culture. Thereby, we aim at elucidating the fundamental relationship between Nietzsche's conceptions of philosophy and of life.

Keywords Nietzsche, medicine, culture, transvaluation, philosophy, life.

\section{I}

Bem se sabe que Nietzsche concebe "o filósofo como médico da cultura". ${ }^{1}$ Essa expressão, que ele chegou a pensar em empregar como título de uma obra em 1873, ganhou uma primeira elucidação nas anotações póstumas dessa época. Ao médico filósofo, então, atribuiu uma tarefa preparatória: a de destruir certas tendências, atenuar outras e liberar outras ainda, tendo em vista a renovação do corpo da cultura.

Contudo, em seus primeiros escritos, Nietzsche já procura ampliar a ideia de sistema vital. Na "Segunda Consideração Extemporânea", ele escreve: "há um grau de insônia, ruminação, sentido histórico, além do qual o ser vivo se desestabiliza e termina por se destruir, pouco importa que se trate de um indivíduo, um povo ou uma cultura". ${ }^{2}$ Incapaz de esquecer, um indivíduo ou um grupo não consegue digerir todas as suas experiências; por outro lado, consciente do que lhe faz bem, um ser humano ou uma cultura atinge uma condição sadia. Diagnosticando a exacerbação do sentido histórico como um caso de dispepsia aguda, Nietzsche sustenta que ela pode manifestar-se tanto nos indivíduos quanto nos povos ou nas culturas.

Com o tempo, a concepção nietzschiana de filósofo como médico da cultura torna-se mais refinada. É o que podemos notar no prefácio de 1886 à "Gaia Ciência". Lá o autor declara:

1 "Fragmento póstumo 23 [15] do inverno de 1872-1873", KSA 7, p. 545. Salvo indicação em contrário, é de minha responsabilidade a tradução dos textos de Nietzsche aqui citados.

2 "Segunda consideração extemporânea" 1, KSA 1, p. 250. 
Ainda estou à espera de que um médico filosófico, no sentido excepcional da palavra - um médico que tenha o problema da saúde geral do povo, tempo, raça, humanidade, para cuidar -, terá uma vez o ânimo de levar minha suspeita ao ápice e aventurar a proposição: em todo filosofar até agora nunca se tratou de 'verdade', mas de algo outro, digamos saúde, futuro, crescimento, potência, vida... ${ }^{3}$

Então, a tarefa do filósofo como médico da cultura se amplia. Não se limita mais a prescrever modificações de tendências; doravante engloba prescrições para a saúde do corpo. Aliás, é por considerar que os dois tipos de prescrições são do mesmo teor que, em seus últimos escritos, Nietzsche encara o cristianismo e o álcool como os dois grandes narcóticos da Europa. ${ }^{4}$ É nesse mesmo espírito que afirma no "Ecce Homo" que "a luta por direitos iguais é mesmo um sintoma de doença: qualquer médico sabe disso" 5 .

\section{II}

Dos vários aspectos que esse livro surpreendente possui, um atrai em particular a nossa atenção. Nele, Nietzsche apresenta-se ao mesmo tempo como médico e paciente. No início do primeiro capítulo, não hesita em colocar o leitor a par de seus vômitos e enxaquecas, da fraqueza de seu sistema digestivo e sua quase cegueira. Mas, se assim procede, é para afirmar imediatamente depois, no segundo parágrafo, que é "sadio no fundamento". ${ }^{6}$ É precisamente o que ele procurará fazer ver nos parágrafos seguintes, ao relatar suas atitudes sadias: ter um soberano sentimento de distinção (§3), não indispor contra ele mesmo ( $(4)$, não se prestar a retaliações $(\S 5)$, estar livre do ressentimento $(\S 6)$, ser capaz de portar-se como inimigo $(\S 7)$, ter a sensibilidade do instinto de limpeza $(\S 8)$. Até o presente momento, tudo se passa como se suas atitudes sadias decorressem de decisões voluntárias - o que poderia reforçar a ideia defendida outrora de que "Ecce Homo" nada mais é do que um relato autobiográfico. ${ }^{7}$ Afinal, o autor propõe-se a explicar no primeiro capítulo do livro "por que sou tão sábio".

3 "A gaia Ciência", prefácio 2, KSA 3, p. 348, grifos no original. Tradução de Rubens Rodrigues Torres Filho.

4 Cf. por exemplo "Crepúsculo dos ídolos", O que falta aos alemães 2, KSA 6, p. 104. Cf. na mesma direção "O Anticristo" 60, KSA 6, p. 249s.

5 "Ecce Homo", Por que escrevo livros tão bons 5, KSA 6, p. 306. Acerca do uso dos termos médicos nos textos nietzschianos, remetemos à esclarecedora análise de Pasley (1978, pp. 123-158).

6 "Ecce Homo", Por que sou tão sábio 1, KSA 6, p. 266, grifos no original. Tradução de Rubens Rodrigues Torres Filho.

7 Werner Stegmaier e Éric Blondel sustentam com propriedade que o livro "Ecce Homo" não poderia prestar-se a essa interpretação. Cf. Stegmaier (2008) e Blondel (2011). A esse propósito, cf. também Marton (2014), em particular o capítulo intitulado "Ecce Homo: Nietzsche, substantivo próprio ou substantivo comum?", pp. 245-262. 
Contudo, examinados de perto, os parágrafos que constituem esse capítulo trazem constantemente esclarecimentos de outra ordem. Nietzsche tem um soberano sentimento de distinção; tomando-se por uma natureza superior, reivindica uma origem mais longínqua como é o caso de todos os grandes homens. Pois "todos os conceitos dominantes sobre os graus de parentesco são um contrassenso fisiológico". ${ }^{8}$ Nietzsche não sabe indispor alguém contra ele mesmo; se em sua vida não houve praticamente nenhum índice de má disposição a seu respeito, suas experiências lhe deram o direito de desconfiar em geral "dos chamados impulsos 'desinteressados"”. Nietzsche não se presta a retaliações contra quem lhe faz uma afronta; mas expressando ao ofensor seu reconhecimento, está longe de calar-se. Pois "todos os calados são dispépticos". Nietzsche está livre do ressentimento; diante daquilo que corre o risco de ferilo, para não consumir-se muito rápido, ele simplesmente não reage. Pois a sede de vingança acarreta "um rápido consumo da força nervosa, um aumento doentio de secreções nocivas, de bile no estômago, por exemplo". Nietzsche é capaz de portar-se como inimigo; sendo uma natureza forte, toma todo obstáculo por estímulo. Pois "atacar faz parte de (s)eus instintos". Nietzsche tem a sensibilidade do instinto de limpeza; se essa sensibilidade não facilita suas relações com os homens, ela permite que perceba "fisiologicamente [...] o mais íntimo, as 'vísceras' de cada alma".

Os elementos reunidos até agora nos permitem afirmar que o autor de "Ecce Homo" estabelece uma estreita relação entre suas atitudes sadias e sua condição fisiológica; bem mais, ao relatar suas atitudes sadias, ele faz o diagnóstico de diferentes condições fisiológicas. É nessa direção que podemos abordar o primeiro parágrafo do capítulo "Por que sou tão sábio" que estamos a examinar.

Então, o filósofo empenha-se em analisar sua dupla origem, que fez dele fruto de um pai morto e de uma mãe que ainda vive. É precisamente essa situação que lhe proporcionou o duplo ponto de vista que marcou sua existência. Para mostrar que seus momentos de baixa vitalidade lhe permitiram enfrentar questões espinhosas, ele associa a esses momentos a elaboração de suas obras, em particular "O Andarilho e sua Sombra" e "Aurora". Para fazer ver que seus estados de saúde lhe dotaram da maestria nas mudanças de perspectiva, expõe as alternâncias dos períodos de restabelecimento e declínio que teve de 
viver. ${ }^{10}$ Atribuindo um valor essencial à doença, Nietzsche soube dela se servir em seu percurso. ${ }^{11}$ Apreciando sua dupla natureza, que fez dele "ao mesmo tempo décadent e começo", soube recobrar a saúde. Se sua condição sadia the proporcionou um ponto de vista para encarar a décadence, suas enfermidades lhe deram um olhar para a saúde. Graças a esse duplo movimento sempre presente em sua vida, tornou-se mestre na arte de "transtrocar perspectivas". Não é por acaso que ele afirma nas últimas linhas desse primeiro parágrafo que está em condição de assumir a tarefa que lhe é destinada: "primeira razão pela qual para mim somente, talvez, é possível em geral uma 'transvaloração dos valores".". ${ }^{12}$

Não hesitamos, pois, em afirmar que, de uma espécie de relato autobiográfico, "Ecce Homo" se converte de uma só vez em texto filosófico. Associando indicações sobre sua condição de vida a suas atitudes sadias, o autor sublinha que elas não são resultado de decisões voluntárias. Ao proporse explicar "por que sou tão sábio", examina o que tornou possível que venha a assumir a tarefa de transvalorar todos os valores.

\section{III}

No segundo capítulo do livro, Nietzsche faz o relato de suas experiências concretas, a começar pelo regime alimentar ( $§ 1)$. Então, prescreve evitar as refeições pesadas, abster-se de beber café, só tomar chá pela manhã. ${ }^{13} \mathrm{Em}$ seguida, trata da questão do lugar e do clima que lhe são propícios (§ 2). Afirma que, graças a um longo aprendizado, agora conhece os efeitos que o clima e a meteorologia podem exercer sobre ele. Convencido de que o ar seco e o céu puro são indispensáveis aos homens cheios de espírito, entende que o clima alemão é nefasto aos que estão destinados a realizar grandes tarefas. Por fim, examina os lazeres que lhe são favoráveis (§ 3). E não hesita em dar exemplos: no que diz respeito à literatura, as poesias de Heinrich Heine, o poema dramático "Manfred", de Byron, e "Hamlet", de Shakespeare (§

10 Cf. "Ecce Homo", Por que sou tão sábio 1, onde Nietzsche escreve: "A partir da ótica do doente, olhar para os conceitos e valores mais sadios e, inversamente, da plenitude e certeza da vida rica, olhar para baixo e ver o secreto trabalho do instinto de décadence - esse foi meu mais longo exercício, minha experiência propriamente dita, e, se é que em algo, foi nisso que me tornei mestre".

11 Cf. "Fragmento póstumo 22 [28] de setembro-outubro de 1888", KSA 13, p. 596, onde Nietzsche escreve: "Tirar proveito de minha enfermidade: a descarga da grande tensão".

12 "Ecce Homo", Por que sou tão sábio 1, KSA 6, p. 266.

13 Nietzsche não hesita em tomar partido quanto a diferentes regimes alimentares; afirma por exemplo que é adversário do vegetarianismo. Posição similar já havia sido tomada por Ludwig Feuerbach. Cf. entre outros textos Feuerbach (1850). 
4); no que concerne a música, "Tristão e Isolda" e o "Idílio de Siegfried", de Wagner, mas também Liszt, Rossini e Peter Gast ( $\S 5, \S 6$ e $\S 7)$. Até o presente momento, tudo se passa como se o regime alimentar a ser seguido por Nietzsche, o lugar e o clima que lhe são propícios e os lazeres que o favorecem decorressem de suas escolhas pessoais - o que poderia reforçar a ideia de que "Ecce Homo" nada mais é do que o relato dos resultados dos experimentos que ele faz com si mesmo. Afinal, o autor do livro propõe-se a explicar no segundo capítulo "por que sou tão esperto".

Contudo, examinados de perto, os parágrafos desse capítulo trazem esclarecimentos que permitem enquadrar de outro modo as experiências de Nietzsche. Indicando seu regime alimentar predileto, ele relaciona a cultura e a cozinha alemãs. ${ }^{14}$ Sustenta que, nascendo com vísceras desarranjadas, "o espírito alemão é uma indigestão, não dá conta de nada”. Voltando-se para a questão do clima e do lugar, insiste na influência da meteorologia sobre o metabolismo. Defende a ideia de que, se uma preguiça intestinal pode fazer de um gênio “algo medíocre, algo 'alemão', o clima alemão por si só basta para desencorajar vísceras fortes e inclusive de disposição heroica". Ocupando-se de seus lazeres, passa em revista suas preferências em matéria de literatura e música. Afirma que é estrangeiro a tudo o que é alemão, "a tal ponto que já a proximidade de um alemão atrasa minha digestão". ${ }^{15}$

Os elementos reunidos até o presente momento permitem notar que, se no primeiro capítulo do livro o autor de "Ecce Homo" relacionava suas atitudes sadias e sua condição fisiológica, no segundo ele estabelece estreita relação entre essa condição e suas escolhas quanto ao regime alimentar, ao lugar, ao clima e aos lazeres. É à mesma lógica que submete tanto suas atitudes quanto o que chama de suas "escolhas". ${ }^{16}$ Se assim procede, é porque concebe o homem como um ser relacional. Insistindo na ideia de que o ser humano está em relação com tudo o que o cerca, não hesita em prescrever: "Ficar sentado

14 Essa ideia está claramente presente na "Genealogia da Moral", em que podemos ler: "o fato de que toda espécie de charlatanismo espiritual tenha sucesso na Alemanha de hoje está ligado à inegável e já palpável devastação do espírito alemão, cuja causa encontro numa alimentação por demais exclusiva, constituída de jornais, política, cerveja e música wagneriana" (“Genealogia da Moral”, Terceira Dissertação 26, KSA 5, p. 407).

15 Cf. respectivamente "Ecce Homo", Por que sou tão esperto 1, KSA 6, p. 280; 2, KSA 6, p. 282; 5, KSA 6, p. 288.

16 Desde a juventude, Nietzsche está convencido da unidade do corpo e do espírito. Numa carta de 1875 a Malwida von Meysenbug, ele escreve: "jamais sofremos apenas corporalmente; tudo está tão profundamente mesclado com crises espirituais que não tenho ideia de como poderei tornar-me outra vez são se recorrer apenas às farmácias e às cozinhas" (Carta a Malwida von Meysenbug de 11 de agosto de $1875, K S B 5$, p. 104, grifos no original). Cf. também a carta a Carl von Gersdorff de 13 de dezembro de 1875, KSB 5, p. 128). 
o menor tempo possível", pois "todos os preconceitos vêm das vísceras". ${ }^{17}$ Mas Nietzsche não se detém aí.

Bem se sabe que, ao longo da vida, o filósofo se pôs à procura das situações mais apropriadas a seu bem-estar. Dedicou-se às mais diversas leituras sobre os regimes alimentares; ${ }^{18}$ lançou-se nos mais diferentes experimentos quanto ao lugar e ao clima. Mas em vez de limitar-se a examinar seu caso particular, transformou em problema filosófico as questões relativas a seu estado de saúde. Da afirmação de que os modos de pensar dependem do sistema digestivo, Nietzsche chega à afirmação de que o espírito funciona da mesma maneira que o sistema digestivo; mais ainda, que o próprio espírito é um sistema digestivo. No caso do espírito como no do estômago, trata-se sempre do poder de assimilação. ${ }^{19}$ Considerando a incorporação um dos mais importantes modos de funcionamento do ser vivo, Nietzsche afirma repetidas vezes que "o espírito é um estômago", ${ }^{20}$ Assim formulada, essa ideia remete diretamente ao núcleo da vertente crítica de seu projeto filosófico. Ao encarar o corpo e o espírito como aliados inseparáveis, ou melhor, como sendo da mesma natureza, o autor de "Ecce Homo" quer romper com o pensamento metafísico. Concebendo o ser humano como uma configuração pulsional ao mesmo tempo física e psíquica, ele se dedica a subverter e ultrapassar toda sorte de dualismos.

Depois de fazer o relato de suas experiências concretas quanto ao regime alimentar a ser seguido, ao lugar e ao clima que lhe são propícios e aos lazeres que o favorecem, o filósofo procura esclarecer o que ele chama de suas "escolhas" no oitavo parágrafo do capítulo "Por que sou tão esperto", que constitui no momento nosso objeto de análise. Então, afirma que em tudo

17 "Ecce Homo", Por que sou tão esperto 1, KSA 6, p. 281, grifos no original.

18 Segundo Andreas Urs Sommer, Nietzsche interessou-se pelos seguintes trabalhos: LÖWENFELD, Leopold. „Die moderne Behandlung der Nervenschwäche (Neurasthenie), der Hysterie und verwandter Leiden“. Mit besonderer Berücksichtigung der Luftcuren, Bäder, Anstaltsbehandlung und der MitchellPlayfair'schen Mastcur, Wiesbaden, 1887; BOCK, Carl Ernst. „Das Buch vom gesunden und kranken Menschen“. Achte, bedeutend vermehrte Auflage, Leipzig, 1870; FOSTER, Michael. „Lehrbuch der Physiologie“. Autorisierte deutsche Ausgabe von N. Kleinenberg. Mit einem Vorwort von W. Kühne, Heidelberg, 1881; CORNARO, Ludwig. „Die Kunst, ein hohes und gesundes Alter zu erreichen“. Neu hrsg. von Paul Sembach, Berlin, 1881. A propósito do interesse de Nietzsche pela dietética, remetemos ao estudo de Sommer (2012).

19 Quanto a esse ponto, Nietzsche poderia muito bem sentir-se atraído pela ideia expressa por Herder: "assim como o corpo aumenta por meio do alimento, o espírito cresce por meio das ideias; com efeito, observamos no caso do espírito as mesmas leis de assimilação, crescimento e produção" (Herder, 1877-1913, Vol. XIII, p. 184).

20 "Assim falava Zaratustra", III Das velhas e novas tábuas 16, KSA 4, p. 258, grifos no original. Cf. também "Para além de Bem e Mal" 230, KSA 5, p. 167; "Fragmento póstumo 26 [141] do verãooutono de 1884", KSA 11, p. 186. 
isso "reina um instinto de autoconservação"; 21 é ele que lhe ordena recusar a entrar em contato com situações desfavoráveis e afastar-se de circunstâncias adversas. Na medida em que lhe é preciso evitar toda espécie de desperdício de energia, seu instinto de conservação se impõe como instinto de autodefesa.

Para tentar apreender o sentido preciso dessa ideia, tomemos em consideração o nono parágrafo do capítulo que estamos a examinar. A análise das reflexões que Nietzsche desenvolve nos permitirá compreender melhor o que chama de suas "escolhas". Tomando como ponto de partida o subtítulo do livro "Ecce Homo", ele começa por afirmar que para tornar-se o que se é, é preciso sobretudo não suspeitar o que se é. Aqui, a divisa socrática se acharia inteiramente deslocada. O filósofo revela, então, que na sua vida jamais esteve consciente da tarefa que se imporia a ele. Sem dela ter conhecimento, seu instinto de conservação organizava e hierarquizava suas competências. É o que procura mostrar na seguinte passagem:

Entrementes, continua a crescer na profundeza a 'ideia' organizadora, chamada a dominar, - ela começa a comandar, lentamente conduz de volta dos caminhos secundários e desvios, prepara qualidades e aptidões isoladas, que um dia se revelarão indispensáveis como meios para o todo, - ela configura uma a uma as faculdades auxiliares, antes mesmo de deixar transparecer algo da tarefa dominante, do 'fim', da 'meta', do 'sentido'. ${ }^{22}$

Em vários textos, Nietzsche sustenta que o corpo consiste numa pluralidade de adversários; ${ }^{23}$ as células assim como os tecidos e os órgãos estão em combate permanente, de sorte que a todo momento qualquer elemento pode vir a predominar ou a perecer. Dessa perspectiva, a luta garante a permanência da mudança; ela faz também com que se estabeleçam hierarquias. Vale insistir que a luta é sem trégua e sem termo; destarte, as hierarquias nunca são definitivas. Afinal, é com processos de dominação que a vida se identifica. ${ }^{24}$

É a essa mesma lógica que obedece ao que Nietzsche chama de suas "faculdades" na passagem de "Ecce Homo" que citamos acima. Então, ele defende a ideia de que, graças ao trabalho do instinto de conservação, seus diferentes impulsos se organizam, de forma a que suas atividades se integrem; entre eles se estabelecem relações de interdependência: uns se submetem a outros, que por sua vez se acham subordinados a outros ainda. Graças a

21 "Ecce Homo", Por que sou tão esperto 8, KSA 6, p. 291.

22 "Ecce Homo", Por que sou tão esperto 9, KSA 6, p. 294, grifos no original.

23 Cf. por exemplo "Fragmento póstumo 2 [76] do outono de 1885-outono de 1886", KSA 12, p. 96.

24 Para aprofundar essa problemática, remetemos ao trabalho de Müller-Lauter (2011). Cf. também Marton (2010), em particular o capítulo intitulado "A constituição cosmológica: vontade de potência, vida e forças", pp. 49-79. 
essa organização hierárquica, arranjando-se com os impulsos de disposição concordante e submetendo os que lhe são opostos, um impulso predominante vem a coordenar todos os demais e a impor-lhes uma direção clara e precisa. ${ }^{25}$

Não é por acaso que Nietzsche encara esse trabalho que o levou a tornarse o que é como "uma obra prima na arte da autoconservação - do egoísmo". ${ }^{26}$ Redefinindo por completo a noção de egoísmo, ele vem recusar a concepção moderna de sujeito. ${ }^{27}$ Concebido como substrato que produz vários efeitos, desenvolve diversas atividades e possui certas propriedades, "o sujeito não é nada além de uma ficção". Entendido como um todo independente, completo, idêntico a si mesmo, permanente e unitário, "o ego é tão-somente um "embuste superior', um 'ideal'”, ${ }^{28}$ No quadro desse egoísmo sem ego, não há lugar para um sujeito que se mantém sempre o mesmo em sua individualidade.

Enquanto força organizadora ou, se se quiser, enquanto "ideia" chamada a dominar, seu instinto de conservação fez em segredo o trabalho de formar uma configuração pulsional destinada à tarefa de transvalorar os valores. $E^{\prime}$ para sublinhar a importância dessa tarefa que Nietzsche se dedicará a fazer o diagnóstico da cultura ocidental no último parágrafo desse capítulo. Nele, podemos ler: "Aquilo que até agora a humanidade ponderou seriamente nem sequer são realidades, são meras imaginações ou, dito mais rigorosamente, mentiras provenientes dos piores instintos de naturezas doentes, perniciosas no sentido mais profundo". ${ }^{29}$ Diante dessa situação, o filósofo entende que já é tempo de desprezar tudo o que até então foi venerado e, pelo mesmo movimento, afirmar tudo o que até então foi negado. Só assim será possível revelar o que por trás dos valores instituídos se esconde e trazer à luz o que eles mesmos escondem. Transvalorar os valores é, antes de mais nada, eliminar o solo a partir do qual os valores foram engendrados e, procedendo a uma inversão, criar novos valores.

25 "Fragmento póstumo 14 [219] da primavera de 1888", KSA 13, p. 394, onde podemos ler: "A multiplicidade e desagregação dos impulsos, a falta de sistema que os reúna resulta em 'vontade fraca'; sua coordenação sob o predomínio de um único resulta em 'vontade forte'; - no primeiro caso, há oscilação e falta de centro de gravidade; no último, precisão e clareza de direção". No primeiro caso, a falta de coesão interna leva à anarquia e, por conseguinte, à decadência; no último, a força organizadora consegue impor uma hierarquia.

26 "Ecce Homo", Por que sou tão esperto 9, KSA 6, p. 293.

27 Para aprofundar essa problemática, remetemos ao estudo de Wotling (2008), em particular ao capítulo intitulado "L'égoïsme contre l'ego. La passion du désintéressement et son sens selon Nietzsche", pp. 251-284.

28 Cf. respectivamente "Fragmento póstumo 9 [108] do outono de 1887", KSA 13, p. 394, grifos no original; "Ecce Homo", Por que escrevo livros tão bons 5, KSA 6, p. 305. A esse propósito, cf. Marton (2011), em particular pp. 114-121 e Marton (2009).

29 "Ecce Homo", Por que sou tão esperto 10, KSA 6, p. 295s, grifos no original. Tradução de Rubens Rodrigues Torres Filho. 
Operando com o procedimento genealógico, Nietzsche afirma que os valores apreciados pela humanidade foram estabelecidos por grandes homens, mas os que foram considerados "os primeiros" não passavam, no fundo, de "vômito da humanidade, aborto de doença e instintos vingativos". Avaliando nesses termos a configuração pulsional dos legisladores de outrora, ele insiste, por contraste, na especificidade de sua própria condição fisiopsicológica. É por ser "sadio no fundamento" que tem "a suprema finura para todos os signos de instintos sadios". ${ }^{30}$

Não hesitamos, pois, em afirmar que de relato dos resultados de experimentos que o autor faz com si mesmo "Ecce Homo" se converte de uma só vez em reflexão filosófica que versa sobre problemas axiológicos. Graças a uma análise refinada e profunda da própria condição fisiopsicológica, Nietzsche mostra que o termo que emprega ao tratar das suas "escolhas" não deve ser tomado no sentido literal. Nem determinações do livre arbítrio nem opções conscientes, suas "escolhas" decorrem do dinamismo dos processos fisiopsicológicos. Ao propor-se a explicar "por que sou tão esperto", além de examinar o que tornou possível que venha a assumir a tarefa de transvalorar todos os valores, como já havia feito no capítulo anterior, ele ressalta a importância dessa tarefa, fazendo para tanto o diagnóstico da cultura ocidental.

\section{IV}

É à luz dessas considerações que é preciso avaliar seu procedimento em "Ecce Homo". É certo que nesse livro Nietzsche pretende que, em vez de deixar-se embalar pelos doutores, ele se tornou seu próprio médico. ${ }^{31}$ Mas se se toma em mãos, é porque nele se manifesta "a incondicional certeza instintiva sobre $o$ que, naquele tempo, era necessário mais que tudo". ${ }^{32}$ Também é certo que sustenta que deu a si mesmo a saúde. Mas se se põe em busca das condições mais apropriadas ao seu bem-estar, é porque nele trabalha em segredo o instinto de conservação.

Como poderíamos, então, compreender que Nietzsche venha a afirmar:

30 "Ecce Homo", Por que sou tão esperto 10, KSA 6, p. 296. Tradução de Rubens Rodrigues Torres Filho.

31 Cf. por exemplo a carta de 1882 a Erwin Rohde, em que Nietzsche considera os livros por ele escritos a partir de 1876 como "minha prescrição e os medicamentos que eu mesmo elaborei contra o fastio da vida". E acrescenta mais adiante: "Se a minha saúde física reaparecer, a quem devo agradecer? Fui em todos aspectos meu próprio médico" (Carta a Erwin Rohde de meados de julho de 1882/ KSB 6, p. 226).

32 "Ecce Homo", Por que sou tão sábio 2, KSA 6, p. 266, grifos no original. Tradução de Rubens Rodrigues Torres Filho. 
"fiz de minha vontade de saúde, de vida, minha filosofia..."? Seria o caso de suspeitar que com essa frase ele estaria retomando a concepção moderna de sujeito? Ao relacionar sua filosofia com sua vontade de saúde, estaria defendendo a ideia de que seu pensamento decorreria de uma decisão voluntária, que sua reflexão filosófica resultaria de uma opção consciente? Ora, se situarmos a frase no seu contexto, seremos levados a interpretá-la de outro modo. No capítulo "Por que sou tão sábio", o autor de "Ecce Homo" escreve:

fiz de minha vontade de saúde, de vida, minha filosofia... Pois prestem atenção a isto: os anos de minha mais baixa vitalidade foram aqueles em que eu deixei de ser pessimista: o instinto do autorrestabelecimento proibiu-me uma filosofia da pobreza e do desânimo. ${ }^{33}$

Nessa passagem, ele começa por estabelecer uma estreita relação entre seu estado de saúde e sua maneira de pensar. Quando trata de suas atitudes sadias e suas "escolhas" quanto ao regime alimentar, ao lugar, ao clima e aos lazeres, deixa entrever que são seus impulsos que lhe prescrevem o tratamento a ser seguido. Quando se volta para sua reflexão filosófica, dá a entender que é sua condição fisiopsicológica que determina a terapêutica que lhe convém. Enfatizando sem cessar o papel de sua configuração pulsional, acaba por atribuir-lhe sua própria filosofia.

Estamos, pois, em condição de compreender o procedimento nietzschiano em "Ecce Homo". No prefácio do livro, o autor considera indispensável apresentar-se, porque será preciso dirigir à humanidade o maior desafio que ela já teve de enfrentar; ao longo dos capítulos, insiste na ideia de que ele nada mais é do que uma configuração pulsional singular. Aliás, é essa ideia que retoma no último capítulo do livro. Propondo-se a explicar "Por que sou um destino", depois de sublinhar a importância da tarefa que lhe é destinada, afirma: "a verdade fala em mim. Mas minha verdade é terrivel: pois até agora à mentira se chamou verdade". ${ }^{34}$ Essa passagem revela em muitos aspectos a atitude que Nietzsche assume em relação à própria reflexão filosófica. Ele dá a entender que são seus impulsos que se exprimem por meio das palavras; bem mais, são eles que tomam a palavra. Se em "Assim falava Zaratustra" o

33 "Ecce Homo", Por que sou tão sábio 2, KSA 6, p. 267, grifos no original. Tradução de Rubens Rodrigues Torres Filho. Cf. ainda "Nietzsche contra Wagner", Epílogo 1, KSA 6, p. 436, em que podemos ler: "No que diz respeito à minha longa enfermidade, não lhe devo indizivelmente mais do que à minha saúde? Devo-lhe uma saúde superior, uma saúde tal que se torna mais forte com tudo o que não a destrói. Devo-Ihe também a minha filosofia...".

34 "Ecce Homo", Por que sou um destino 1, KSA 6, p. 365, grifos no original. 
protagonista aparecia como "o porta-voz da vida, o porta-voz do sofrimento, o porta-voz do círculo", ${ }^{35} \mathrm{em}$ "Ecce Homo" é também como porta-voz que Nietzsche se apresenta. Afinal, é sua condição fisiopsicológica que lhe dita a própria filosofia. É precisamente o que ele parece dar a entender na continuação do texto que estamos a examinar. Tanto é que escreve: "Transvaloração de todos os valores: essa é a minha fórmula para um ato de suprema autognose da humanidade, que em mim se fez carne e gênio". ${ }^{36}$ Daí se depreende que é sua configuração pulsional que determina a sua tarefa, que lhe impõe transvalorar os valores. Presente no seu corpo e no seu espírito, que são uma única e mesma coisa, ou seja, imposta pela sua própria condição fisiopsicológica, a transvaloração de todos os valores será incorporada por Nietzsche e através dele expressa.

\section{V}

Somos tentados a afirmar que, dessa perspectiva, "Ecce Homo" se apresenta como uma espécie de tratado de medicina. Nesse livro, por um lado, Nietzsche faz um duplo diagnóstico: de início, o de seu caso particular e, em seguida, o da cultura ocidental. Por outro, apresenta uma dupla terapêutica: de início, a que seus impulsos lhe prescrevem para tornar-se o que é e, em seguida, a que sua configuração pulsional lhe impõe para curar o ser humano, a saber, a transvaloração de todos os valores. Esse é o procedimento que permite que de médico de si mesmo Nietzsche se converta em médico da cultura.

\section{Referências}

BLONDEL, É. "Do sujeito de Ecce Homo. O eu, a jovialidade e o alciônico". Tradução de Vinicius de Andrade. In: I. Silva Júnior (ed.), 2011. pp. 29-54.

BOCK, C. E. "Das Buch vom gesunden und kranken Menschen". Achte, bedeutend vermehrte Auflage. Leipzig, 1870.

CORNARO, L. "Die Kunst, ein hohes und gesundes Alter zu erreichen”. Berlin, 1881. FEUERBACH, L. "Die Naturwissenschaft und die Revolution". In: Blätter für literarische Unterhaltung, Nr. 268-271 (de 8 a 12 de novembro de 1850), pp. 1069-1083.

FOSTER, M. "Lehrbuch der Physiologie. Autorisierte deutsche Ausgabe von N. Kleinenberg. Mit einem Vorwort von W. Kühne”. Heidelberg, 1881.

HERDER. "Sämtliche Werke”. Ed. Bernhard Suphan. Berlin: Weidmann, 1877-1913. 
LÖWENFELD, L. "Die moderne Behandlung der Nervenschwäche (Neurasthenie), der Hysterie und verwandter Leiden. Mit besonderer Berücksichtigung der Luftcuren, Bäder, Anstaltsbehandlung und der Mitchell-Playfair'schen Mastcur”. Wiesbaden, 1887. MARTON, S. "Do dilaceramento do sujeito à plenitude dionisíaca". Cadernos Nietzsche, Vol. 25, pp. 53-81, 2009.

. "Nietzsche e a arte de decifrar enigmas". São Paulo: Loyola, 2014.

. "Nietzsche, das forças cósmicas aos valores humanos". $3^{\mathrm{a}}$ ed. Belo Horizonte: Ed. UFMG, 2010.

. "Nietzsche, Kant et la métaphysique dogmatique". Nietzsche-Studien, Vol. 40, pp. 106-129, 2011.

MÜLLER-LAUTER, W. "Nietzsche, sua filosofia dos antagonismos e os antagonismos de sua filosofia”. Tradução de Clademir Araldi. São Paulo: Ed. Unifesp, 2011.

NIETZSCHE, F. "Obras incompletas". Tradução de Rubens Rodrigues Torres Filho. $2^{a}$ ed. São Paulo: Abril Cultural, 1972 (Col. "Os Pensadores").

. "Sämtliche Briefe". Kritische Studienausgabe $(K S B)$. Ed. Giorgio Colli e Mazzino Montinari. Berlim: Walter de Gruyter \& Co, 1986. 6 Vols.

. "Sämtliche Werke". Kritische Studienausgabe (KSA). Ed. Giorgio Colli e Mazzino Montinari. Berlim: Walter de Gruyter \& Co, 1967/1978. 15 Vols.

PASLEY, M. (ed.). "Nietzsche: Imagery and Thought”. Berkeley: University of California Press, 1978.

. "Nietzsche's use of medical terms". In: M. Pasley (ed.), 1978. pp. 123-158.

SILVA JÚNIOR, I. (ed.). "Filosofia e cultura. Festschrift para Scarlett Marton”. São Paulo: Barcarolla, 2011.

SOMMER, A. U. "Inwiefern ist Ernährung ein philosophisches Problem? Ludwig Feuerbach und Friedrich Nietzsche als Relativierungsdenker". Perspektiven der Philosophie, Vol. 38, pp. 319-342, 2012.

STEGMAIER, W. "Schicksal Nietzsche? Zu Nietzsches Selbsteinschätzung als Schicksal der Philosophie und der Menschheit (Ecce Homo, Warum ich Schicksal bin 1)". Nietzsche-Studien, Vol. 37, pp. 62-114, 2008.

WOTLING, P. "La philosophie de l'esprit libre. Introduction à Nietzsche". Paris: Flammarion, 2008. 